\title{
FEMTOSECOND LASER SETTINGS FOR OPTIMAL BRACKET BONDING TO ZIRCONIA
}

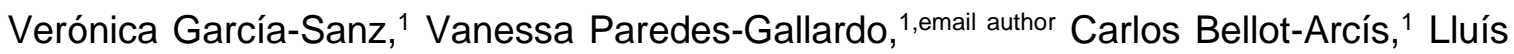
Martínez-León, ${ }^{2}$ Rafael Torres-Mendieta, ${ }^{3}$ Javier Montero, ${ }^{4}$ and Alberto Albaladejo. ${ }^{4}$

1 Orthodontics Teaching Unit, Faculty of Medicine and DentistryUniversity of Valencia, Valencia (Spain).

2 GROC.UJI, Institute of New Imaging Technologies, Universitat Jaume I, Castelló de la Plana (Spain).

3 Institute for Nanomaterials, Advanced Technologies and Innovation, Technical University of Liberec, Liberec (Czech Republic).

4 Orthodontics Teaching Unit, Department of Surgery, Faculty of Medicine, University of Salamanca, Salamanca (Spain).

\section{ABSTRACT}

Bonding orthodontic brackets to ceramic materials is a challenging procedure; femtosecond (FS) laser conditioning could provide improved results, but the ideal settings for effective bracket-zirconia bonding have never been established. This study aimed to: analyze the differences in surface roughness and shear bond strength (SBS) produced by different femtosecond laser settings and establish a protocol to prepare zirconia surfaces for optimal adhesion to metal orthodontic brackets. One hundred and eighty zirconia samples were assigned to six groups according to surface treatment: 1- control; 2- air-particle abrasion (APA); 3- FS laser irradiation (300mW output power, 60 $\mathrm{mm}$ inter-groove distance); 4- FS laser irradiation $(200 \mathrm{~mW}, 100 \mu \mathrm{m}), 5-\mathrm{FS}$ laser irradiation $(40 \mathrm{~mW}, 60 \mu \mathrm{m})$, and 6- FS laser irradiation $(200 \mathrm{~mW}, 60 \mu \mathrm{m})$. Surface roughness was measured. Orthodontic brackets were bonded to the zirconia specimens and SBS was measured. SBS in Groups 3 and 6 was significantly higher than the other groups $(5.92 \pm 1.12 \mathrm{MPa}$ and $5.68 \pm 0.94 \mathrm{MPa}$ ). No significant differences were found between groups 1 , 2, 4 and $5(3.87 \pm 0.77 \mathrm{MPa}, 4.25 \pm 0.51 \mathrm{MPa}, 3.74 \pm 0.10 \mathrm{MPa}$ and $3.91 \pm 0.53$ 
$\mathrm{MPa}$ ). Surface roughness was significantly greater for FS laser than for control and APA groups $\left(p=1.28 \times 10^{-8}\right)$. FS laser at $200 \mathrm{~mW}, 60 \mu \mathrm{m}$ can be recommended as the ideal settings for treating zirconia surfaces, producing good SBS and more economical energy use.

\section{Key words:}

Femtosecond laser -Dental ceramic - Orthodontic brackets - Pulsed laser -Adhesion · Surface roughness

\section{INTRODUCTION}

In recent years increasing demand for orthodontic treatment from adult patients has been developing. Many of these patients have ceramic dental restorations, but bonding brackets to these surfaces can present a challenge due to the properties of the ceramic materials, which are less porous than dental tissues, and, together with glazing, hinder the creation of microretention [1]. For this reason, it is necessary to determine a bonding protocol that will provide an efficient and durable bracket-porcelain bond meeting the requirements of orthodontic treatment, although bonding must be reversible with minimal damage to the surfaces. Reynolds established the optimal range for orthodontic bonding as between 5.9 and $7.8 \mathrm{MPa}$ [2].

Zirconia is an effective and highly aesthetic dental ceramic and so there has been much interest in researching bracket bonding procedures to this surface [3]. A range of surface conditioning techniques have been proposed to enhance the bonding of different materials to ceramic, including sandblasting [3,4], silica coating [5], etching with hydrofluoric acid [6], $\mathrm{CO}_{2}$ and Er:YAG laser irradiation [710]. 
The latest in vitro investigations have included femtosecond laser, which several authors have proposed for enhancing bond strength to enamel $[11,12]$, dentin [13], and porcelain surfaces [14].

Ti:Sapphire Femtosecond (FS) laser emits ultrashort pulses in the femtoseconds range ( $1 \mathrm{fs}=10^{-15} \mathrm{~s}$ ) [15], with a low transfer of heat to the irradiated material [16]. Other lasers used in dentistry present higher rates of heat transfer [17-19] as their pulse duration falls within the picosecond and nanosecond ranges.

Femtosecond laser has been used in several recent in vitro investigations of ceramic surface conditioning in preparation for bonding $[14,20]$. Only two studies have evaluated the shear bond strength (SBS) of orthodontic metallic brackets bonded to ceramic surfaces treated with femtosecond laser [21,22]; both works used feldspathic ceramic. To date, no studies have analyzed the SBS of brackets bonded to zirconia, despite this being the most commonly used ceramic material for prosthetic restorations in adult patients.

Previous research into FS lasers has employed various different settings, leading to a notable lack of consensus between results [14,20-22]. In this context, assaying different FS laser settings could determine a gold standard for optimal bracket to zirconia bonding, providing a benchmark for future research and for optimizing clinical outcomes.

Moreover, establishing the most efficient processing conditions could help to address one of the biggest drawbacks of FS laser systems - their high cost [22]. 
Roughness tests performed by profilometers are a reliable method of assessing the effects of porcelain surface treatments [23] and several authors have studied the relationship between surface irregularities and shear bond strength [24]. Both surface roughness and shear bond strength could depend on the laser settings used.

The purpose of this study was to determine the ideal femtosecond laser settings in terms of output power and inter-groove distance when preparing zirconia surfaces, to optimize the shear bond strength of orthodontic brackets.

\section{MATERIALS AND METHODS}

\section{Specimen preparation}

This in vitro assay used a sample of 180 Y-TZP zirconia (Cercon®), Degudent, Hanau, Germany) square plates $(9 \times 9 \times 1 \mathrm{~mm})$.

\section{Experimental design}

All specimens were polished with 600-grit silicon carbide paper to remove imperfections and obtain uniform surfaces. The specimens were randomly divided into 6 groups $(n=30)$ according to the surface treatment applied. After conditioning the samples with different surface treatments, each group was divided into two subgroups $(n=15)$. One subgroup was analyzed for surface roughness, and the other for shear bond strength. Fig. 1 shows a diagram of the experimental design.

\section{Surface treatment groups}


Group 1: (Control). No treatment applied to zirconia surfaces.

Group 2: (Air Particle Abrasion [APA]) Surfaces were sandblasted with alumina particles $\left(\mathrm{Al}_{2} \mathrm{O}_{3}\right)$ with an average size of $25 \mu \mathrm{m}$ at a pressure of $0.25 \mathrm{MPa}$ for 20 seconds at a perpendicular distance of $10 \mathrm{~mm}$ from the specimen. The treatment was applied to the entire surface area.

In Groups 3, 4, 5 and 6, zirconia surfaces were irradiated by femtosecond Ti:Sapphire laser (Femtopower Compact Pro, Femtolasers) with a pulse width of $30 \mathrm{fs}$, full width at half maximum (FWHM) at a central wavelength of $800 \mathrm{~nm}$, and a repetition rate of $1 \mathrm{kHz}$ for 12 minutes. The whole surface $(9 \times 9 \mathrm{~mm})$ was irradiated. A programmable acousto-optic filter (Dazzler, Fastlite) was used to ensure the time compression of laser pulses at the interaction spot between zirconia samples and laser radiation, by controlling the amplitude and pulse phase. As a standard feature of the laser system used, the acousto-optic filter was installed in the cavity of the multipass pulse amplification stage. The incoming laser beam passed through an iris diaphragm with a diameter of $6 \mathrm{~mm}$ at the $1 / \mathrm{e}^{2}$ width, and after using a plano-convex lens with a focal length of 75 $\mathrm{mm}$, the beam was focused onto the sample surface, and the irradiated spot was $20.6 \mu \mathrm{m}$ (FWHM). The samples were placed on the surface of a $2 \mathrm{D}$ motion controlled stage moving at a constant speed of $1.44 \mathrm{~mm} / \mathrm{s}$ in both $\mathrm{X}$ and $\mathrm{Y}$ directions in the plane of the laser beam focus, following a raster pattern. Different combinations of output power $(\mathrm{mW})$ and inter-groove distances $(\mu \mathrm{m})$ were applied as follows:

- Group 3: output power of $300 \mathrm{~mW}$, inter-groove distance of $60 \mu \mathrm{m}$.

- Group 4: output power of $200 \mathrm{~mW}$, inter-groove distance of $100 \mu \mathrm{m}$. 
- Group 5: output power of $40 \mathrm{~mW}$, inter-groove distance of $60 \mu \mathrm{m}$.

- Group 6: output power of $200 \mathrm{~mW}$, inter-groove distance of $60 \mu \mathrm{m}$.

\section{Surface roughness analysis}

Roughness measurements ( $R a$ in $\mathrm{k} \AA$ ) of the specimens were registered using a stylus profiler (6M Veeco Dektak, Plainview, NY), the Ra value representing the mean roughness of each surface.

Four scans of $500 \mu \mathrm{m}$ were performed for each specimen placing the stylus at different locations. For the laser groups, the scanning direction was set perpendicular to the laser-traced lines.

\section{Bracket bonding procedure}

One upper incisor orthodontic metal bracket (Victory 3M Unitek, Monrovia, Calif, USA) measuring $3 \times 4 \mathrm{~mm}$, was bonded at the centre of each treated zirconia specimen using a total etch adhesive system (Transbond TM XT; 3M-Unitek). To polymerize both the primer and the adhesive layer, a curing light (XL 3000, 3M ESPE) at $500 \mathrm{~mW} / \mathrm{cm}^{2}$ intensity was applied to the bracket-zirconia sample directed at the occlusal and gingival bracket edges for 20 seconds.

Samples were stored in distilled water at $37^{\circ} \mathrm{C}$ for 24 hours.

\section{Shear Bond Strength (SBS) Test}

All bonded samples were mounted perpendicularly on acrylic resin bases and a shear load was applied using a universal testing machine (AGS-X Autograph, Shimadzu Corporation, Kyoto, Japan), at a crosshead speed of $0.5 \mathrm{~mm} / \mathrm{min}$, until bracket-zirconia separation. SBS values were calculated in MPa by dividing the 
maximum load recorded at the moment of bond failure (Newtons, N) by the bracket area $\left(12 \mathrm{~mm}^{2}\right)$.

\section{Bond failure analysis}

After debonding, the zirconia surfaces were examined at $40 \times$ magnification using an Axio M1 light microscope (Carl Zeiss, Oberkochen, Germany). The adhesive remnant index (ARI), proposed by Årtun and Bergland [25] was used to classify each failure as one of four categories according to the amount of cement remaining on the ceramic surface: 1) No remaining cement; 2) $<50 \%$ of cement remaining; 3) $>50 \%$ of cement remaining; 4) All the cement remaining.

\section{Scanning Electron Microscopy (SEM) Analysis}

One additional porcelain specimen was prepared for each experimental group to perform qualitative analysis of the surface using scanning electron microscopy (SEM) (JEOL-JSM-7001F, JEOL Ltd., Tokyo, Japan) at 350× magnification.

Representative samples from each group were also examined by SEM at $75 x$ magnification after debonding to compare morphological variations between the debonded surfaces in different treatment groups.

\section{Statistical analysis}

Surface roughness data (measured in $\mathrm{kA}$ ) and SBS values (in MPa) were analyzed using SPSS v.16 software (Statistical Package for the Social Sciences, Chicago, IL, USA). 
Descriptive statistics, means, standard deviation (SD), median, minimum and maximum surface roughness $(\mathrm{kA})$ and SBS (MPa) were calculated; 95\% confidence intervals were also included.

Two-way analysis of variance (ANOVA), and Tamhane's T2 multiple comparison test were used to determine the statistical significance of the differences in mean variables between groups and Spearman's coefficient was used to calculate the non-linear correlation between SBS and surface roughness. Statistical significance was set at $p<0.05$.

Lastly, Kruskal-Wallis and multiple Mann-Whitney tests applying Bonferroni correction were used to assess the homogeneity of ARI index data between groups.

\section{RESULTS}

\section{Shear Bond Strength (SBS)}

Table 1 shows the SBS values (MPa) obtained in all groups. All surface treatments affected SBS, obtaining higher values in comparison with the control group except for Group 4. Groups 3 and 6 presented higher SBS but without significant differences between the two groups $(5.92 \pm 1.12 \mathrm{MPa}$ and $5.68 \pm 0.94$ $\mathrm{MPa}$ ), while Groups 1 (control) and 4 showed lower values $(3.87 \pm 0.77 \mathrm{MPa}$ and $3.74 \pm 0.10 \mathrm{MPa}$, respectively). No statistically significant differences were found between Groups 1, 2, 4 and 5.

According to these results, higher output power values produced higher SBS, although the difference in SBS between $200 \mathrm{~mW}$ and $300 \mathrm{~mW}$ was not statistically significant $(p=0.128)$. 


\section{Surface roughness}

Table 2 shows mean surface roughness values ( $R a$ in $k A ̊)$ obtained in each treatment group.

All treated groups showed rougher surfaces than the control group $\left(p=1.28 \times 10^{-}\right.$ 8). Laser treatments produced significantly deeper grooves on the zirconia surfaces than air particle abrasion $\left(p=1.28 \times 10^{-8}\right)$, Group 4 showed the highest Ra $(106.24 \pm 4.93 \mathrm{k} \AA)$. No statistically significant differences were found between Groups 3 and $6(p=0.595)$.

The results show that power outputs of 300 and $200 \mathrm{~mW}$ produced significantly higher Ra values compared with 40mW $\left(p=1,25 \times 10^{-6}\right.$ and $p=1.28 \times 10^{-8}$ respectively); differences between 300 and $200 \mathrm{~mW}$ roughness values did not show statistical significance $(p=0.051)$.

\section{Correlation between surface roughness and SBS}

In general terms, increases in surface roughness tended to increase SBS values. However, when Ra values exceeded a threshold value of $100 \mathrm{kA}$, SBS decreased $(r=0.217 ; p=0.040)$ (Fig. 2).

\section{Bond failure}

Table 3 shows bond failure types in all groups. In three of the FS laser groups (3,

4 and 6) $50-80 \%$ of the samples showed failure types 3 and 4 . These results showed significant differences $(p<0.001)$ compared with the failure modes 
obtained by groups $1\left(p=1.28 \times 10^{-8}\right), 2\left(p=1.25 \times 10^{-6}, p=2.04 \times 10^{-5}\right.$ and $p=$ $1.25 \times 10^{-6}$ respectively) and $5\left(p=1.25 \times 10^{-6}, p=2.04 \times 10^{-5}\right.$ and $p=1.25 \times 10^{-6}$ respectively), which presented types 1 and 2 only.

\section{SEM}

Differences in surface morphology can be observed in SEM images of the specimens at 350x magnification (Fig. 3a). The control group shows a smooth surface; the $\mathrm{APA} \mathrm{Al}_{2} \mathrm{O}_{3}$ sample shows a granulated surface; and $\mathrm{FS}$ laser groups $(3,4,5$ and 6$)$ show deep and precise grooves, which were especially marked in Group 4.

Fig $3 b$ shows SEM images of representative samples from each group after debonding. Groups 1, 2 and 5 show very small amounts of resin cement on the zirconia surface. But large amounts of cement remnant can be observed in groups 3, 4 and 6.

\section{DISCUSSION}

While many methods have been proposed for conditioning ceramic surfaces prior to bonding orthodontic brackets, conditioning protocols have not been standardized $[3,5-8,10]$.

The present study aimed to assess the surface roughness of zirconia surfaces treated with different femtosecond laser parameters, and to measure the SBS of metal brackets bonded to these surfaces, in order to determine which laser protocol obtains optimal bond strength. 
Different lasers have been assayed as ceramic conditioners for bracket bonding: $\mathrm{Nd}: Y A G, E r: Y A G, \mathrm{CO}_{2}$ and Ti:Sapphire, femtosecond lasers being the most commonly reported $[1,21,22,26]$.

Femtosecond lasers are considered to cause less damage to the irradiated surfaces since they have a null or only very slight heating effect [16]. Given that temperature increases greater than $5.5{ }^{\circ} \mathrm{C}$ can produce irreversible damage to dental pulp [27], and ceramic materials have low temperature-shielding effects [28], femtosecond lasers constitute the ideal device for irradiating these surfaces. Nevertheless, Ti:Sapphire femtosecond laser is a very expensive instrument and its large dimensions make everyday use in medical clinics inconvenient. Fiberoptic-based femtosecond lasers offer a cheaper, smaller and more resistant option than conventional Ti:Sapphire lasers and have partly overcome the drawbacks of the earlier equipment [29]. But the peak intensities do not reach the capabilities offered by Ti:Sapphire lasers, a key factor affecting processing depth, and so the SBS of metal brackets bonded to zirconia.

Only two studies have investigated the effect of FS laser on the SBS of brackets bonded to porcelain $[21,22]$. In contrast to other lasers, research into FS laser surface treatment for orthodontic bonding on ceramics has not established the ideal output power settings for obtaining optimal shear bond strength. Akpinar et al. (2015) applied $750 \mathrm{~mW}$ to condition samples [21], while Erdur and Basciftci (2015) applied output power of $400 \mathrm{~mW}$ [22].

The present study compared different mean power outputs to prepare zirconia surfaces. The trade-off between the speed of sample preparation and the most 
advantageous laser powers was considered at a preliminary calibration stage, and three typical mean power values were chosen, ranging from the highest power achievable at the micromachining station, to the lowest, including a third intermediate power: $300 \mathrm{~mW}, 40 \mathrm{~mW}$, and $200 \mathrm{~mW}$, respectively. Displacement of the translation stage along the $y$ direction was set at $60 \mu \mathrm{m}$ for the three mean power groups. For the $200 \mathrm{~mW}$ setting, a $100 \mu \mathrm{m}$ step was also tested in an attempt to reduce preparation time.

The highest SBS values were obtained in Groups $3(300 \mathrm{~mW} 60 \mu \mathrm{m})$ and 6

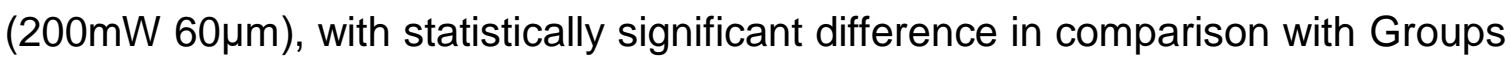
$4(200 \mathrm{~mW}, 100 \mu \mathrm{m})$ and $5(40 \mathrm{~mW}, 60 \mu \mathrm{m})$. Akpinar et al. (2015) and Erdur and Basciftci (2015), obtained higher SBS values than the present study [21,22]. But while these authors used FS laser as in the present study, the conditioned ceramic was not zirconia. Moreover, the laser power settings chosen were higher than in the present assay. Excessive output powers may compromise the aesthetics of the ceramic surface irreversibly, so it is important to establish a balance between bond strength and minimal surface damage. These differences in study protocols could explain the different results obtained. According to the existing literature, the findings of these earlier studies exceed the optimal SBS range suggested for orthodontic adhesion [2], while the results obtained in the present investigation fall within the range considered adequate.

To our knowledge, no other study has analyzed bracket adhesion to FS lasertreated zirconia. Other authors have investigated other lasers used to condition zirconia $[1,26]$. These lasers have been reported to have adverse effects on surrounding structures (thermal damage, for example) $[17,30]$. The present study assayed femtosecond laser, as it is known to provide gentle, homogeneous and 
precise surface etching, does not produce degradation of the surrounding materials [31], and does not raise the temperature of the ablated surface [16].

Other authors have analyzed the SBS of resin to femtosecond laser-irradiated zirconia surfaces. In agreement with the present findings, Vicente Prieto et al. obtained higher values for a femtosecond laser group compared with traditional surface treatment methods [32]. Kara et al. analyzed the SBS of resin to zirconia treated with different lasers, obtaining higher values with femtosecond laser [33].

Regarding the effect of lasers other than FS on the SBS of resin to ceramic surfaces, studies have not obtained significant differences between lasers and air particle abrasion groups [34].

The present study also assessed surface roughness ( $R a$ in $k \AA ̊$ ) quantitatively. SEM was used to analyze surface morphology qualitatively. Several previous studies have analyzed the effects of different lasers on the surface roughness of dental materials $[24,33,35,36]$. Two works compared the effects of three lasers (femtosecond, Nd:YAG and Er:YAG) on the roughness of ceramic surfaces, both obtaining significantly greater roughness values in the femtosecond laser group $[33,36]$. In the present study, all FS laser groups showed significantly higher $R a$ values than the control and air particle abrasion groups, Group 4 (FS $200 \mathrm{~mW}$ $100 \mu \mathrm{m})$ presenting the deepest irregularities. These characteristics were also observed in SEM images (Fig. 3a).

Relating surface roughness to SBS values, a positive correlation was found for all laser groups except Group 4. Groups 1, 2 and 5 all showed low Ra and SBS 
values, while Groups 3 and 6 (FS laser at $300 \mathrm{~mW} 60 \mu \mathrm{m}$, and $200 \mathrm{~mW} 60 \mu \mathrm{m}$ ) showed high Ra and SBS values.

These results suggest that surface roughness depends on both average laser output power and inter-groove distance. A tendency for SBS to increase as Ra values increase was also observed.

Erdur and Basciftci (2015) obtained similar Ra values to the present study [36].

Regarding bond failure, a high percentage of the samples in Groups 3, 4 and 6 showed debond types 3 and 4 (bond failure between cement and bracket), findings that are consistent with the literature [21]. But Groups 1, 2 and 5 (FS laser at $40 \mathrm{~mW} 60 \mu \mathrm{m}$ ) presented bond failure types 1 and 2 . These were probably caused by insufficient depth of surface irregularities preventing the adhesive from penetrating adequately, an observation confirmed by surface roughness analysis. Failure mode 4 is the most conservative for the porcelain, as no surface fracture occurs at debonding [37]. These findings concur with the present SBS results, since the groups obtaining higher SBS values were found to retain greater amounts of cement on the ceramic surfaces. This is an important fact to take into consideration when referring to bracket-zirconia bonding, which ideally should be reversible, as the porcelain surface will be exposed after bracket removal. According to our results, FS laser at $300 \mathrm{~mW} 60 \mu \mathrm{m}$ and FS laser at $200 \mathrm{~mW} 60 \mu \mathrm{m}$ (Groups 3 and 6) were the least damaging treatments in this regard.

The irradiation time per sample reported in the present study (12 minutes) might represent a limitation. However, if only the area covered by the bracket base was to be irradiated, the estimated irradiation time would be 1.8 minutes, which is 
acceptable for this matter. Furthermore, it would be possible to split the fundamental laser beam, thus multiple laser beams could be used to process more than one sample at a time, or reduce the processing time.

This study of the SBS of brackets bonded to zirconia using different femtosecond laser settings could serve as a guide for further research. The present findings suggest that femtosecond laser at $200 \mathrm{~mW}$ mean power and $60 \mu \mathrm{m}$ inter-groove distance are ideal parameters for conditioning zirconia surfaces before bonding metal brackets, as these settings provide adequate bond strength. Even though similar SBS results were obtained setting the FS laser at $300 \mathrm{~mW}$ and $60 \mu \mathrm{m}$, the differences between the two settings were not statistically significant, and as the latter option involves greater energy use, the former would appear to be the better option. These parameters would appear to represent ideal settings for the following reasons: firstly, they obtained adequate SBS outcomes $(5.68 \pm 0.94$ $\mathrm{MPa}$ ), which fall into the range proposed by Reynolds for orthodontic bonding (5.9 to $7.8 \mathrm{MPa}$ ) [2]; secondly, they obtained good results in terms of the amount of resin remnant, since $60 \%$ of the samples in Group 6 presented type 4 failure, which is the most conservative for the ceramic surface; thirdly, the patterns observed on the surfaces irradiated by the FS laser were homogeneous, as shown by roughness analysis and SEM images.

Although in vitro research has shown that FS lasers offer advantages in terms of SBS, the conditioning technique has not been tested clinically due to current laser system costs and dimensions. Further research and development are required before they can be introduced routinely in dental practice. 


\section{CONCLUSIONS}

- Femtosecond laser at $300 \mathrm{~mW}$ and $200 \mathrm{~mW}$ mean power and $60 \mu \mathrm{m}$ step provides higher SBS for metal brackets bonded to zirconia.

- The surface roughness of zirconia conditioned with FS laser is directly correlated to SBS, providing Ra values do not exceed 100kÅ.

- Femtosecond laser irradiation settings at $200 \mathrm{~mW}$, with an inter-groove distance of $60 \mu \mathrm{m}$ are proposed as the optimal settings for treating zirconia surfaces for maximum orthodontic bracket SBS.

\section{NOTES}

\section{Compliance with ethical standards}

\section{Conflict of interest}

The authors declare no conflict of interest.

\section{Funding}

The present research received financial support from the Generalitat Valenciana through the project PROMETEU/2016/079, the Ministerio de Economía y Competitividad (MINECO) through the project FIS2016-75618-R, and the Ministry of Education Youth and Sports of the Czech Republic through project No. LM2015073. The authors declared no conflicts of interest regarding research, authorship, and/or publication of this article.

\section{Ethical approval}

This article does not contain any procedures involving human participants or animals performed by any of the authors.

\section{Informed consent}


For this type of study, formal consent is not required.

\section{REFERENCES}

1. Poosti M, Jahanbin A, Mahdavi P, Mehrnoush S (2012) Ceramic conditioning with Nd:YAG and Er:YAG laser for bracket bonding in orthodontics. Lasers Med Sci 27:321-24

2. Reynolds IR (1975) A review of direct orthodontic bonding. Br J Orthod 2:1718

3. Gomes AL, Oyagüe RC, Lynch CD, Montero J, Albaladejo A (2013) Influence of sandblasting granulometry and resin cement composition on microtensile bond strength to zirconia ceramic for dental prosthetic frameworks. J Dent $41: 31-41$

4. Mosharraf R, Rismanchian M, Savabi O, Ashtiani AH (2011) Influence of surface modification techniques on shear bond strength between different zirconia cores and veneering ceramics. Journal Adv Prosthodont 3:221-8

5. Spohr AM, Borges GA, Júnior LH, Mota EG, Oshima HM (2008) Surface modification of In-Ceram Zirconia ceramic by Nd:YAG laser, Rocatec system, or aluminum oxide sandblasting and its bond strength to a resin cement. Photomed Laser Surg 26:203-8

6. Usumez A, Hamdemirci N, Koroglu BY, Simsek I, Parlar O, Sari T (2013) Bond strength of resin cement to zirconia ceramic with different surface treatments. Lasers Med Sci 28:259-66 
7. Cavalcanti A,Foxton RM, Watson TF, Oliveira MT, GianniniM, Marchi GM (2009) Bond strength of resin cements to a zirconia ceramic with different surface treatments. Oper Dent 34:280-328

8. Akin H, OzkurtZ, Kımalı O, KazazogluE, Ozdemir (2011) Shear bond strength of resin cement to zirconia ceramic after aluminium oxide sandblasting and various laser treatments. Photomed Laser Surg 29:797-802

9. Paranhos MP, Burnett LH Jr, Magne P (2011) Effect of Nd:YAG laser and $\mathrm{CO} 2$ laser treatment on the resin bond strength to zirconia ceramic. Quintessence Int 42:79-89

10. Gomes AL, Ramos JC, Santos-del Riego S, Montero J, Albaladejo A (2015) Thermocycling effect on microshear bond strength to zirconia ceramic using Er:YAG and tribochemical silica coating as surface conditioning. Lasers Med Sci 30:787-95

11. Lorenzo MC, Portillo M, Moreno P, Montero J, Castillo-Oyagüe R, García A, Albaladejo A (2014) In vitro analysis of femtosecond laser as an alternative to acid etching for achieving suitable bond strength of brackets to human enamel. Lasers Med Sci 29:897-905

12. Lorenzo MC, Portillo M, Moreno P, Montero J, García A, Santos-del Riego SE,Albaladejo A (2015) Ultrashort pulsed laser conditioning of human enamel: in vitro study of the influence of geometrical processing parameters on shear bond strength of orthodontic brackets. Lasers Med Sci 30:891-900

13. Portillo M, Lorenzo MC, Moreno P, García A, Montero J, Ceballos L, FuentesMV, Albaladejo A (2015) Influence of Er:YAG and Ti:sapphire laser irradiation on the microtensile bond strength of several adhesives to dentin. Lasers Med Sci 30:483-92 
14. Vicente M, Gomes AL, Montero J, Rosel E, Seoane V, Albaladejo A (2016) Influence of cyclic loading on the adhesive effectiveness of resin-zirconia interface after femtosecond laser irradiation and conventional surface treatments. Lasers Surg Med 48:36-44

15. Moulton PF (1986) Spectroscopic and laser characteristics of Ti: Al2O3. J Opt Soc Am 3:125-33

16. Varel H, Ashkenasi D, Rosenfeld A, Wähmer M, Campbell EEB (1997) Micromachining of quartz with ultrashort laser pulses. Applied Physics A65:367-73

17. Armengol V, Jean A, Marion D (2000) Temperature rise during Er:YAG and Nd:YAP laser ablation of dentin. J Endod 26:138-41

18. Braun A, Krillke RF, Frentzen M, Bourauel C, Stark H, Schelle F (2015) Heat generation caused by ablation of dental hard tissues with an ultrashort pulse laser (USPL) system. Lasers Med Sci 30:475-81

19. Cavalcanti BN, Lage-Marques JL, Rode SM (2003) Pulpal temperature increases with Er:YAG laser and high-speed handpieces. J Prosthet Dent $90: 447-51$

20. Akpinar YZ, Kepceoglu A, Yavuz T, Aslan MA, Demirtag Z, Kılıc HS, UsumezA (2015) Effect of femtosecond laser beam angle on bond strength of zirconiaresin cement. Lasers Med Sci 30:2123-8

21. Akpinar YZ, Irgin C, Yavuz T, Aslan MA, Kilic HS, Usumez A (2015) Effect of femtosecond laser treatment on the shear bond strength of a metal bracket to prepared porcelain surface. Photomed Laser Surg 33:206-12 
22. Erdur EA, Basciftci FA (2015) Effect of Ti:sapphire laser on shear bond strength of orthodontic brackets to ceramic surfaces. Lasers Surg Med 47:5129

23. Tholt de Vasconcellos B, Miranda-Júnior WG, Prioli R, Thompson J, Oda M (2016) Surface roughness in ceramics with different finishing techniques using atomic force microscope and profilometer. Oper Dent 31:442-9

24. Ersu B, Yuzugullu B, Ruya Yazici A, Canay S (2009) Surface roughness and bond strengths of glass-infiltrated alumina-ceramics prepared using various surface treatments. J Dent 37:848-56

25. Artun J, Bergland S (1984) Clinical trials with crystal growth conditioning as an alternative to acid-etch enamel pretreatment. Am J Orthod 85:333-40

26. Ahrari F, Heravi F, Hosseini $\mathrm{M}$ (2013) $\mathrm{CO}_{2}$ laser conditioning of porcelain surfaces for bonding metal orthodontic brackets. Lasers Med Sci 28:1091-7

27. Brown WS, Dewey WA, Jacobs HR (1970) Thermal properties of teeth. J Dent Res 49:752-5

28. Kuo WC, Chang YH, Lin CL, Kuo JS (2011) Effects of different ceramic and dentin thicknesses on the temperature rise during photocuring. J Dent Sci $6: 210-5$

29. Chong A, Wright LG, Wise FW (2015). Ultrafast fiber lasers based on selfsimilar pulse evolution: a review of current progress. Rep Prog Phys $78: 113901$

30. Malmström HS, McCormack SM, Fried D, Featherstone JD (2001) Effect of $\mathrm{CO} 2$ laser on pulpal temperature and surface morphology: an in vitro study. $\mathrm{J}$ Dent 29:521-9 
31. Fiedler S et al. (2001) Machining of biocompatible ceramics with femtosecond laser pulses. Biomed Tech (Berl) 58:Suppl.1

32. Vicente Prieto M, Gomes ALC, Montero Martín J, Alvarado Lorenzo A, Seoane Mato V, Albaladejo Martínez A (2016) The Effect of Femtosecond Laser Treatment on the Effectiveness of Resin-Zirconia Adhesive: An In Vitro Study. J Lasers Med Sci 7:214-219

33. Kara O, Kara HB, Tobi ES, Ozturk AN, Kilic HS (2015) Effect of various lasers on the bond strength of two zirconia ceramics. Photomed Laser Surg 33:69-76

34. García-Sanz V, Paredes-Gallardo V, Mendoza-Yero O, Carbonell-Leal M, Albaladejo A, Montiel-Company JM, Bellot-Arcís C (2018) The effects of lasers on bond strength to ceramic materials: A systematic review and meta-analysis. PLoS One 13:e0190736

35. Çağlar İ, Yanıkoğlu N (2016) The Effect of Sandblasting, Er:YAG Laser, and Heat Treatment on the Mechanical Properties of Different Zirconia Cores. Photomed Laser Surg 34:17-26

36. Erdu EA, Basciftci FA (2015) Effect of Ti:Sapphire-femtosecond laser on the surface roughness of ceramics. Lasers Surg Med 47:833-8

37. Smith GA, Mclnnes-Ledoux P, Ledoux WR, Weinberg R (1998) Orthodontic bonding to porcelain-bond strength and refinishing. Am J Orthod Dentofacial Orthop 94:245-52 


\section{FIGURES}

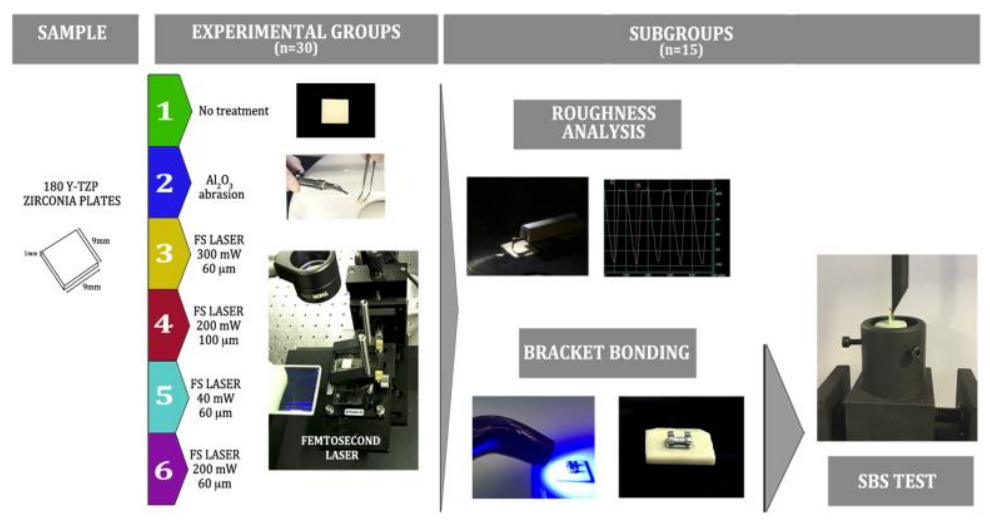

Figure 1. Experimental design diagram.

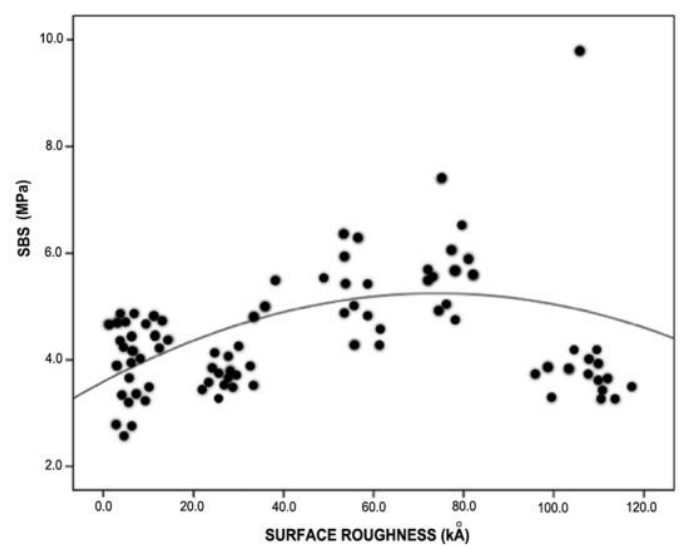

Figure 2. Matrix plot relating SBS to surface roughness.
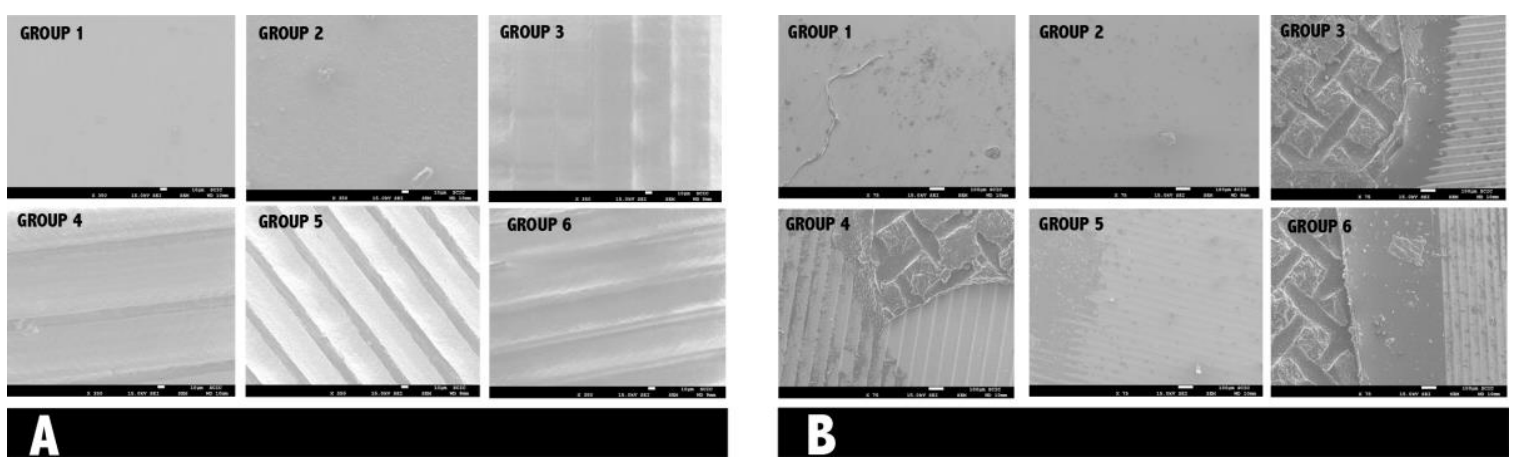

Figure 3. a) SEM images of zirconia after surface conditioning, at $350 \times$ magnification;

b) SEM images of zirconia after debonding, at $75 \times$ magnification. 


\section{TABLES}

Table 1. SBS values (MPa) for each experimental group

\begin{tabular}{|c|c|c|c|c|c|c|c|}
\hline & \multicolumn{7}{|c|}{ EXPERIMENTAL GROUPS } \\
\hline & Total & $\begin{array}{c}1 \\
\text { CONTROL }\end{array}$ & $\stackrel{2}{\text { APA Al }_{2} \mathrm{O}_{3}}$ & $\begin{array}{c}3 \\
\text { FS } 300 \mathrm{~mW} 60 \mu \mathrm{m}\end{array}$ & $\begin{array}{c}\stackrel{4}{\text { FS } 200 \mathrm{~mW} 100 \mu \mathrm{m}} \\
\text {. }\end{array}$ & $\begin{array}{c}\mathbf{5} \\
\text { FS 40mW } 60 \mu \mathrm{m}\end{array}$ & $\begin{array}{c}6 \\
\text { FS } 200 \mathrm{~mW} 60 \mu \mathrm{m}\end{array}$ \\
\hline $\mathbf{N}$ & 90 & 15 & 15 & 15 & 15 & 15 & 15 \\
\hline Mean & 4.56 & 3.87 & 4.25 & 5.92 & 3.74 & 3.91 & 5.68 \\
\hline Standard Deviation (SD) & 1.38 & 0.77 & 0.51 & 1.12 & 0.10 & 0.53 & 0.94 \\
\hline * & & c & bc & $a b$ & c & c & a \\
\hline
\end{tabular}

* values with the same letter are not statistically different $(p>0.05)$ 
Table 2. Surface roughness values (Ra in kÅ) for each experimental group.

\begin{tabular}{|c|c|c|c|c|c|c|c|}
\hline & \multicolumn{7}{|c|}{ EXPERIMENTAL GROUPS } \\
\hline & Total & $\begin{array}{c}1 \\
\text { Control }\end{array}$ & $\begin{array}{c}2 \\
\mathrm{APA} \mathrm{Al}_{2} \mathrm{O}_{3}\end{array}$ & $\begin{array}{c}3 \\
\text { FS } 300 \mathrm{~mW} 60 \mu \mathrm{m}\end{array}$ & $\begin{array}{c}4 \\
\text { FS } 200 \mathrm{~mW} 100 \mu \mathrm{m}\end{array}$ & $\begin{array}{c}\mathbf{5} \\
\text { FS } 40 \mathrm{~mW} 60 \mu \mathrm{m}\end{array}$ & $\begin{array}{c}6 \\
\text { FS } 200 \mathrm{~mW} 60 \mu \mathrm{m}\end{array}$ \\
\hline$N$ & 90 & 15 & 15 & 15 & 15 & 15 & 15 \\
\hline Mean & 45.93 & 2.87 & 8.52 & 67.51 & 106.24 & 27.97 & 62.50 \\
\hline Standard Deviation (SD) & 38.43 & 0.90 & 2.42 & 26.77 & 4.93 & 2.95 & 10.44 \\
\hline * & & $\mathrm{e}$ & $d$ & $\mathrm{~b}$ & a & c & $\mathrm{b}$ \\
\hline
\end{tabular}

* values with the same letter are not statistically different $(p>0.05)$ 
Table 3. Bond failure mode results

\begin{tabular}{|c|c|c|c|c|c|c|c|c|c|c|c|c|c|c|}
\hline & \multicolumn{14}{|c|}{ GROUPS } \\
\hline Total & 90 & $100 \%$ & 15 & $100 \%$ & 15 & $100 \%$ & 15 & $100 \%$ & 15 & $100 \%$ & 15 & $100 \%$ & 15 & $100 \%$ \\
\hline Type 1 & 33 & $36,7 \%$ & 15 & $100 \%$ & 8 & $53.3 \%$ & 0 & $0 \%$ & 0 & $0 \%$ & 10 & $66.6 \%$ & 0 & $0 \%$ \\
\hline Type 3 & 16 & $16,7 \%$ & 0 & $0 \%$ & 1 & $6.7 \%$ & 4 & $26.7 \%$ & 8 & $53.3 \%$ & 0 & $0 \%$ & 3 & $20 \%$ \\
\hline Type 4 & 17 & $20,0 \%$ & 0 & $0 \%$ & 0 & $0 \%$ & 8 & $53.3 \%$ & 0 & $0 \%$ & 0 & $0 \%$ & 9 & $60 \%$ \\
\hline * & & & $\mathrm{b}$ & & $b$ & & a & & a & & $b$ & & a & \\
\hline
\end{tabular}

* groups with different letters are statistically different $(p<0.001)$ 